\section{Cambio e institucionalización de la "nueva derecha" chilena (1967-2010)}

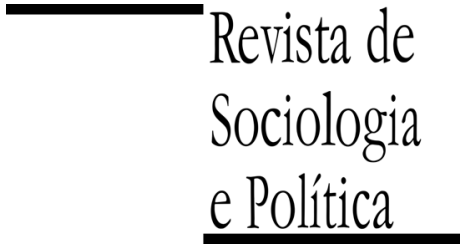

DOI 10.1590/1678-987314225209

\author{
Stéphanie Alenda
}

RESUMEN

En este artículo, analizamos las continuidades y cambios del partido más grande de Chile en número de votos y escaños: la Unión Demócrata Independiente (UDI); en un período que va desde sus inicios como movimiento universitario gremial a fines de los años sesenta hasta el año 2010, cuando la UDI deja de ser un partido de oposición para integrar la coalición de gobierno de centro-derecha, Alianza por Chile. Inspirándonos en la tipología de Mahoney y Thelen (2010), planteamos que la UDI conoció un proceso de cambio gradual que implicó una conservación y fortalecimiento en el tiempo de sus reglas y procedimientos rutinizados, no obstante reinterpretados por sucesivas generaciones de dirigentes. Conectamos este planteamiento con los aportes de la sociología de la institución de inspiración bourdiana, para mostrar que la institucionalización de la UDI resulta de una doble dinámica: el ajuste a un orden particular de habitus adaptados/adaptables, y la emergencia de procesos de desajuste/distanciamiento que se traducen por la aparición paulatina de oposiciones generacionales y posicionales, entre actores y grupos de actores quienes asignan objetivos distintos a su compromiso y al partido. Estudiamos esta doble dinámica siguiendo la evolución de la relación partidista inicial que adopta la forma de una "comunidad" (Weber) en "sociedad", tomando en cuenta los factores tanto exógenos como endógenos del cambio. Este trabajo, que descansa en diferentes tipos de fuentes (entrevistas biográficas con los máximos dirigentes de la UDI; encuesta sociográfica a delegados y archivos de prensa), aprehende así la institucionalización partidista como un proceso dinámico e interactivo, iniciado mucho antes del acta de nacimiento oficial del partido.

PALABRAS-CLAVE: Derecha chilena; Sociología de las instituciones partidistas; Unión Demócrata Independiente; Institucionalización partidista; Cultura institucional.

Recebido em 15 de Março de 2014. Aprovado em 30 de Outubro de 2014.

\section{Introducción ${ }^{1}$}

$\mathrm{E}$ 124 de septiembre de 1983, bajo la dictadura del general Pinochet, la Unión Demócrata Independiente (UDI) es fundada por un grupo de ex dirigentes estudiantiles. La etapa inicial de esta organización que se transformará en partido político en 1988 transcurre sin embargo a fines de los años sesenta, cuando la UDI da sus primeros pasos como movimiento "gremial"2. Tiene como principal ideólogo a Jaime Guzmán, quien preside el Centro de alumnos de la Facultad de Derecho de la Universidad Católica (UC) en 1967, año en el que se producen movilizaciones para la democratización de la educación superior. La federación de estudiantes de esta Universidad (la FEUC), entonces dirigida por el partido demócrata-cristiano (PDC), juega un rol clave en la organización de la protesta que desemboca en la toma de la Casa central el 11 de agosto de 1967. La medida provoca la reacción de un grupo minoritario, dando impulso a la constitución formal del movimiento, cuya influencia se irá asentando al interior de la FEUC ${ }^{3}$. Su doctrina, inspirada en el corporativismo franquista, se caracteriza por denunciar las influencias ideológicas sobre los gremios, la Iglesia y el PDC. Convertido en profesor de derecho constitucional de la Universidad Católica, Guzmán desempeña un papel clave en el reclutamiento y la formación de la segunda generación de dirigentes gremialistas y en la constitución de una comunidad moral que se da como misión la "reconstrucción nacional". Después del golpe de Estado de 1973, el movimiento se estructura, sus miembros participan en diferentes niveles del 
humano y político (Guzmán 1991, p. 6). Entre 1969 y 1985, los gremialistas controlan la presidencia de la FEUC.

${ }^{4}$ Declaración de principios de la UDI, El Mercurio, 24 de septiembre de 1983.

5 Joaquín Lavín construye su notoriedad política siendo alcalde de una de las comunas más ricas de Santiago (Las Condes), entre 1992 y 1999. aparato público y realizan un trabajo de proselitismo que concurre al mantenimiento del régimen.

La segunda etapa del movimiento se inicia a principios de los años ochenta, marcadas por importantes manifestaciones. Tras un plebiscito fraudulento, una nueva Constitución es promulgada en 1980 de la que Jaime Guzmán es uno de los redactores. No obstante, la crisis económica de los años 1982-1983 conduce a un recrudecimiento de las movilizaciones y obliga al régimen a la apertura. Los gremialistas emprenden entonces la estructuración de un movimiento político con miras a la futura legalización de los partidos y la vuelta a la democracia, lo que les conduce a intensificar su trabajo de reclutamiento y formación. El movimiento que nace en 1983 descansa en tres principios: se define como "popular" pero con el objetivo explícito de terminar con la lucha de clases; de "inspiración cristiana", y defiende la economía de mercado instalada durante la dictadura ${ }^{4}$. Son así sentadas las bases del partido político finalmente fundado en 1988, en la efervescencia del plebiscito.

Bajo muchos aspectos, la trayectoria de la UDI puede parecer excepcional: la organización sobrevive a la caída de un régimen al que brindó un apoyo irrestricto, y a dos principales reconfiguraciones internas: la primera luego del asesinato de su leader e ideólogo Jaime Guzmán en 1991; la segunda en torno al fenómeno Lavín 5 , momento en el que se produce una ampliación de las bases militantes y electorales del partido. Éste conoce entonces un despegue inédito para la derecha desde la vuelta a la democracia en 1989.

¿Cómo la UDI logra mantenerse en el tiempo hasta convertirse en el partido más importante de Chile en número de votos y escaños? ${ }^{6}$ Descifrar las razones de tal éxito nos obligará a volver sobre los orígenes del movimiento para estudiar la eclosión y evolución de cierto tipo de compromiso total que nace a fines de los años sesenta, la constitución de sólidas redes de influencia bajo la dictadura; pero también el establecimiento de una cultura jerárquica y de un reclutamiento selectivo tendiente a preservar la homogeneidad de una institución socializadora y disciplinaria.

\section{Analizar el cambio en una "institución fuerte"}

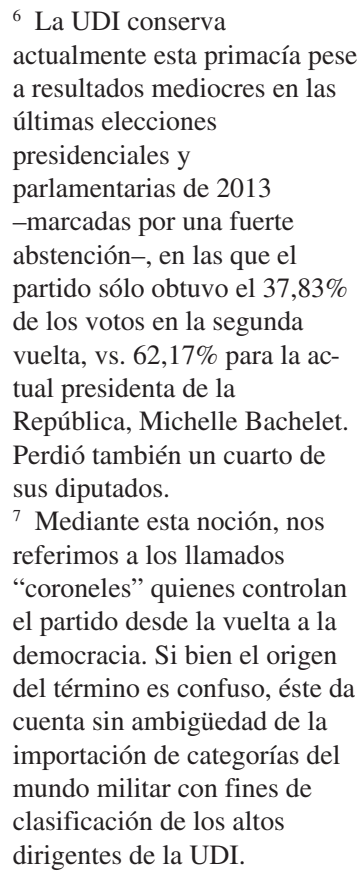

La UDI puede ser considerada como una "institución fuerte" (Panebianco 1990 [1982]) o como un partido fuertemente institucionalizado, tomando como criterios de evaluación los rasgos organizacionales asociados con la institucionalización en la investigación sobre los partidos políticos. Conserva una elevada cohesión estructural; se caracteriza por contar con una "coalición dominante" eficaz para disciplinar a la periferia de la organización y repartir incentivos (idem, p. 418); demostró estabilidad en el tiempo, además de ser exitosa electoralmente; como partido doctrinario, adquirió también un valor propio ligado a su preservación, más allá de los intereses particulares de sus integrantes. Por último, cuenta con reglas y procedimientos rutinizados, practicados y aceptados por sus miembros ${ }^{8}$.

En el marco de este artículo, desarrollaremos en particular este último aspecto, partiendo del planteamiento según el cual una alta rutinización no constituye un impedimento para la adaptación de un partido político a cambios del entorno o a ciertos remezones internos y que, por ende, la institucionalización, así entendida, no reduciría la capacidad adaptativa de las organizaciones. Matizaremos así la hipótesis de Steven Levitsky ${ }^{9}$ formulada a partir del estudio del Partido Justicialista argentino - y extendida a otros partidos de base sindical en América Latina -, cuya rápida adopción de reformas neoliberales durante la presidencia de Carlos Menem fue al contrario posible por tratarse de un partido "débilmente institucionalizado", con una estructura 
${ }^{8}$ Sobre este tercer criterio, ver entre otros a (North 1990, p. 3; O’Donnell 1994, pp. 57-59).

9 Ver también la tesis de Panebianco sobre los procesos de institucionalización (Panebianco 1990, pp. 114-125).

${ }^{10}$ Ver el estudio de Kitschelt (1994) sobre los partidos socialdemócratas europeos.

${ }^{11}$ Para una ilustración de la conversión institucional aplicada a otras instituciones que los partidos, remitimos a Levitsky y Murillo (s.d., p. 17).

${ }^{12}$ Cf. al respecto el capítulo

"Institucionalismo

sociológico" en Peters (1999, pp. 147-166)

${ }^{13}$ Remitimos también al libro de Pierson (2004).

14 Ver la amplia literatura sobre path dependence y los debates posteriores que abren paso a lecturas del cambio, de carácter menos dramático y más procesual (Collier \& Collier 1991; Pierson 2004; Peters, Pierre \& King 2005; Olsen 2009, entre otros).

${ }_{15}$ Ver entre otras referencias a Helmke y Levitsky (2006).

${ }^{16}$ Aquello cobra particular relevancia para estudiar a la UDI, dada la importancia otorgada a la formación de sus cuadros y dirigentes. interna "fluida" que le dio flexibilidad (Levitsky 2003). Acogeremos más bien la tesis según la cual lo que varía de una institución a otra es el patrón de cambio que se suele observar (Levitsky \& Murillo 2010): los partidos fuertemente institucionalizados tenderían así a adaptarse al cambio de manera más gradual y lenta ${ }^{10}$ que las instituciones débiles.

La teoría del cambio institucional propone precisamente diferenciar aquellas variaciones a través de una tipología de patrones de cambio incremental (Mahoney \& Thelen 2010), que hace derivar el cambio de la especificidad de las propiedades institucionales, asociadas a su vez a diferentes tipos de agentes de cambio, en el marco de contextos particulares (idem, pp. 16-17). Esta teoría distingue asimismo diferentes formas evolutivas de las instituciones: el injerto de nuevas reglas sobre las viejas ("superposición"), la atrofía gradual ("desvío"), la pérdida de relevancia ("desplazamiento") o los cambios en su función ("conversión"). Rescatando este último patrón, en el que los actores buscan cambiar ciertas prácticas, dejando sin embargo intactas las reglas vigentes, mostraremos que la UDI conoció un proceso de cambio gradual que consistió en una conservación en el tiempo de reglas y procedimientos rutinizados, no obstante reinterpretados estratégicamente por los dirigentes ${ }^{11}$. Aquello implica enfocar a las instituciones como "entidades construidas socialmente por las percepciones y cogniciones de sus miembros" (Peters 2003, p. 160) ${ }^{12}$, teniendo en cuenta que estos aspectos cognitivos no han sido en general abordados mediante un estudio empírico del perfil sociográfico de los actores del cambio, de sus socializaciones, y trayectorias al interior de la organización.

Inspirándonos en la teoría de Mahoney \& Thelen ${ }^{13}$, abogaremos también por un enfoque sobre el cambio alternativo a los planteamientos institucionalistas que tienden a ver éste como una excepción a la regla de la estabilidad institucional, recalcan las propiedades auto-reproductivas de las instituciones (Jepperson 1991, p. 145); o conciben a menudo éste como el resultado exclusivo de "eventos críticos", shocks exógenos o cambios del entorno ${ }^{14}$. Introduciremos así algunos matices a la definición de la adaptación partidaria formulada por Levitsky (2003, p. 9), entendiendo ésta como una serie de modificaciones incrementales en la estrategia y/o estructura, adoptadas en respuesta a cambios en condiciones tanto exógenas como endógenas.

Por último, nos interesaremos principalmente por los aspectos de la rutinización llamados "informales" en la literatura especializada ${ }^{15}$, que "moldean la forma en que los partidos funcionan" (Freidenberg \& Levistky 2006, p. 195), en mayor medida que las reglas oficiales contenidas en sus estatutos. Como señala Panebianco: "los estatutos son sólo una pálida huella, enormemente lábil e imprecisa; poco más que un punto de partida en el análisis organizativo de un partido político" (Panebianco 1990, p. 87). Por ejemplo, éstos son poco explícitos en cuanto a los requisitos para hacer carrera en alguna de las ramas de la organización o acerca de quién(es) controla(n) los mecanismos de ascenso interno; también respecto a los procedimientos concretos de reclutamiento y selección de candidatos. Corresponde más bien al investigador objetivar los aspectos de una institucionalización "informal", que depende de la capacidad de los partidos para inculcar a sus miembros esquemas de percepción, de pensamiento y de acción duraderos (los habitus, según Bourdieu), los mismos que regulan, aunque informalmente, el diario vivir partidario, plasmándose en reglas, roles diferenciados, y en una cultura específica ${ }^{16}$.

Planteamos asimismo como hipótesis que la institucionalización de la UDI es fruto de una doble dinámica: el ajuste a un orden particular de habitus adaptados/adaptables, y la emergencia de procesos de desajuste/distanciamiento que se traducen por la aparición paulatina de oposiciones generacionales y posicionales entre actores y grupos de actores quienes asignan objetivos distintos a su 
17 Ver a Weber (1995, pp. 78-82).

${ }^{18}$ Remitimos más ampliamente al libro Sociologie de l'institution (Lagroye \& Offerlé 2011). En El Sentido Práctico (Bourdieu 1980, pp. 95-96), Bourdieu habla por su parte de la "dialéctica entre los habitus y las instituciones". compromiso y al partido. Para testear esta hipótesis, nos interesaremos por diferentes dimensiones de la reproducción y del cambio institucional: por una parte, la conservación en el tiempo de las reglas y procedimientos rutinizados al interior del partido abordado a través de $i$ ) su producción y rutinización; ii) la fábrica y reproducción de cierto tipo de líderes y de carrera dirigencial; iii) la continuidad en el tiempo de cierta forma de socialización (la "comunidad" entendida en el sentido weberiano ${ }^{17}$ ). Por otra parte, estudiaremos el cambio partidista a través de $i$ ) la conversión de esta comunidad en "sociedad" (Weber 1995, pp. 78-82) y sus efectos sobre las reglas internas ii) la capacidad de agencia de los actores quienes, a partir de experiencias socializadoras diferenciadas, resignifican las reglas existentes sin subvertirlas. Esta perspectiva nos permitirá articular en un mismo marco de análisis las reglas y los jugadores, habitualmente disociados en la literatura especializada (North 1990, pp. 4-5), enfocando a la "institución partidista" como producto de la dialéctica entre las prácticas individuales que hacen existir tipos particulares de asociación y las conductas autorizadas en ellos (Fretel 2011, pp. 195-196 ${ }^{18}$ ).

En la primera parte de este artículo, reconstruiremos las condiciones históricas de emergencia de un movimiento político generacional que se asemeja, en sus inicios, a una comunidad moral. En la segunda, mostraremos como ese "Nosotros" se solidifica en una marca distintiva, mientras se constituye progresivamente una "cultura institucional". Este sistema de valores y de prácticas nace entonces en el marco de la colaboración de los gremialistas con el régimen militar, período durante el cual éstos hacen un aprendizaje diferenciado del rol de líder, al mismo tiempo que se cristalizan ciertas reglas de reclutamiento y funcionamiento de la organización. En una tercera parte, daremos cuenta por un lado de la preservación de la comunidad moral inicial, comparando el perfil y las trayectorias de diferentes cohortes de dirigentes y candidatos al parlamento; y, por el otro, de la conversión de este modelo inicial en un partido político competitivo, en el marco del cual suceden los procesos de desajuste/distancimiento mencionados.

Este artículo está basado en una investigación llevada a cabo sobre los dirigentes del principal partido de la derecha chilena entre los años 2006 y 2009, en el marco de los proyectos FONDECYT No 1061034 y VID SOC07/29-02. Recurre a tres tipos de fuentes: entrevistas biográficas realizadas con los dirigentes de la UDI que forman parte de su núcleo fundador, en las que indagamos en sus socializaciones (familiar, religiosa, política y partidaria), reclutamiento y trayectorias (ver síntesis en el Anexo 1); una encuesta sociográfica que nos permitirá comparar el perfil de tres cohortes de delegados; por último, archivos de prensa, mediante los cuales identificamos, por un lado, patrones de reproducción entre las trayectorias del núcleo fundador y de los dirigentes más jóvenes (candidatos en las elecciones legislativas de 2009) y precisamos, por el otro, la doctrina inicial de la agrupación y sus primeros rasgos organizacionales.

\section{Génesis de una comunidad moral}

${ }^{19}$ En 1987, la perspectiva del regreso a la democracia lleva diferentes agrupaciones de
Según Panebianco, dos factores inciden mayormente en la estructura organizativa de un partido, explican su fisonomía y funcionamiento: su historia organizativa (su pasado) y su relación con el entorno (Panebianco 1990). De ahí la importancia de preguntarse por sus orígenes, el perfil de sus fundadores, la sociogénesis de sus reglas para posteriormente descifrar las modalidades de la estructuración y funcionamiento partidista. Como vimos, la UDI nace en 1983 como movimiento y en 1988 como partido ${ }^{19}$. Sin embargo, la reconstrucción de su "primo-génesis" (Aït-Aoudia \& Dézé 2011), vale decir las interacciones previas entre actores, sus posiciones, modos de involucramiento, recursos, diná- 
derecha a conformar un nuevo partido político de "centro-derecha" bautizado Renovación Nacional. Al término de una lucha entre dirigentes por su control, se deshace la alianza. La UDI emprende su reconstrucción primero como movimiento "UDI por el sî" de cara al plebiscito, luego en 1988 , como partido político.

${ }^{20}$ Para mayores detalles sobre este período, remitimos al libro de Collier \& Sater 1999, pp. 278-279. micas de agregación y de exclusión, nos obliga a tomar como punto de partida los años sesenta para estudiar los primeros pasos del movimiento que se convertirá en partido, en base a la movilización de redes universitarias, profesionales y populares preexistentes.

El movimiento gremial nace en reacción a la expansión del marxismo, en un país que es entonces probablemente el más politizado y radicalizado de América Latina ${ }^{20}$. Tras la elección de Salvador Allende en 1970, los gremialistas buscan canalizar las demandas de diferentes gremios (principalmente agricultores, comerciantes y transportistas) y organizaciones civiles, opuestas al gobierno. Esta "nueva derecha" se alza también sobre las ruinas de la derecha tradicional, incapaz de interpretar las transformaciones sociales que afectan entonces al país (ver entre otros a Valdivia Ortiz de Zárate 2008).

¿Cuál es el origen de este nuevo referente político? ¿Cuál es el perfil de los gremialistas que terminarán siendo los máximos dirigentes de la UDI? Siguiendo las intuiciones de Karl Mannheim, éstos pueden ser analizados como una "unidad de generación". En efecto, se trata por un lado de un grupo de individuos quienes comparten una posición similar en un acontecer sociohistórico específico (III.1) en el cual es forjado una "nueva" doctrina y es definido cierto perfil de miembro (III.2); pero quienes son sobre todo socializados en una misma instancia donde se teje el sentimiento de pertenecer a una "comunidad de destino" (Mannheim 1993, pp. 223 y 225) (III.3). Abordaremos estos tres puntos a continuación.

\section{III.1. Posiciones, acontecer socio-histórico y unidad de generación}

${ }^{21}$ Entre los fundadores de la UDI, conviene distinguir la primera generación de dirigentes de la segunda. Los dos presidentes de la UDI de más edad, Jaime Guzmán y Jovino Novoa formaron parte de los partidos conservador y liberal, respectivamente. En cambio, entre los dirigentes de la segunda generación, Juan Antonio Coloma es el único en reconocer un vínculo absoluto con la derecha.

${ }^{22}$ Escisión del partido conservador en 1936 que da lugar a la fundación del PDC en 1957.
Los fundadores de la UDI provienen en general de familias de agricultores acomodadas, que tienen en común una trayectoria de movilidad ascendente. Sin embargo, la mayoría no pertenece a la derecha tradicional, y no todos adhieren al partido nacional (PN) que irrumpe en el escenario político en 1966 tras el declive de las dos principales fuerzas de la derecha tradicional: los partidos conservador y liberal ${ }^{21}$. La socialización política de estos futuros dirigentes dista en efecto mucho de ser unívoca. El padre de Hernán Larraín es uno de los fundadores de la Falange nacional ${ }^{22}$; Julio Dittborn es cercano a la Democracia Cristiana; por su parte, la familia Chadwick Piñera juega de su diversidad para estar presente en la vida política chilena desde los años sesenta. Mientras el padre de Andrés Chadwick hace fortuna durante el régimen de Pinochet, su tío milita en el partido socialista del que sale electo senador en 1965. Una tercera rama -la de los Piñera- es demócrata-cristiana.

La conciencia social de los futuros líderes de la UDI encuentra así sus raíces en un catolicismo característico de diferentes sensibilidades políticas que van de la derecha a la centro-derecha. Se forja también a veces al contacto de referentes de la política nacional ubicados a la izquierda del espectro político. Por último, es reforzada en el marco de la institución escolar. Durante el gobierno de la Unidad Popular (1970-1973), los futuros gremialistas (en particular los miembros de la segunda generación) son escolarizados en liceos católicos emblemáticos de Santiago y formados por curas partidarios de la doctrina social de la Iglesia, entonces favorable a la lucha de clases. Bajo diferentes modalidades, variables en función de la penetración más o menos fuerte de las ideas del concilio ecuménico en cada institución, entran en contacto con el mundo poblacional, sea a raíz de la integración a su colegio de niños de escasos recursos, sea en el marco de actividades solidarias realizadas en los barrios populares.

El desarrollo de esta conciencia social debe ser por lo tanto entendida a la luz del habitus católico y de clase de estos jóvenes, lo que ilustra particularmente 
bien la experiencia de uno de los principales referentes de la UDI, Pablo Longueira, durante sus años de colegio. A los dieciséis años, éste se encuentra en un barrio marginal, junto a un grupo de compañeros, en el marco de actividades organizadas por los jesuitas. Cuando un cura empieza a "predicarles la lucha de clases", el futuro líder se siente agredido por el contenido de un discurso que echa abajo el "esfuerzo" de sus padres por elevarse socialmente (su padre, administrador de fundo, había obtenido una parcela de la reforma agraria), recalcando la "profunda conciencia social" de éstos:

"El choque entre ambas visiones me produjo, pese a mi juventud, un enorme rechazo a lo que percibí en la conversación nocturna como un intento de manipulación de mi sensibilidad social. Indudablemente en muchos de mis compañeros de colegio el efecto fue otro, pero en mi caso personal, a ese hecho yo le asigno el no haber sido de izquierda" (Longueira 2003, p. 80).

Este testimonio es revelador de un efecto de histéresis de los habitus -según la expresión de Pierre Bourdieu-, habitualmente asociada a una inadaptación de los actores a las nuevas condiciones del espacio social. Traduciéndose por un repliegue sobre disposiciones iniciales ligadas a la clase y a la práctica religiosa, este fenómeno se produce, en varios casos de dirigentes entrevistados, a medida que la radicalización socio-política anterior al golpe de Estado acentúa la percepción de que una amenaza pesa sobre las capas dominantes. Este sentir desembocará en una "contra-revolución", vale decir un proyecto de contrasociedad, vivido como un tipo específico de compromiso moral y patriótico, el cual adoptará los rasgos de una "revolución capitalista modernizadora" (Moulián 1993, p. 286) bajo el régimen militar.

\section{III.2. La eclosión de una doctrina}

El registro de justificación de esta "contra-revolución" se enraíza en una visión religiosa y conservadora del orden social. Para los gremialistas, el punto de partida es la reconquista de la Universidad Católica que se pretende reencauzar, reconvirtiéndola en "una verdadera familia y en un auténtico mensaje cristiano” (Movimiento Gremial, FEUC, 1969).

La contra-revolución tiene por su parte como objetivo rectificar la tendencia de algunos sectores de inspiración cristiana - presentes en la Iglesia y la Democracia Cristiana- que se dejaron seducir por la "utopía anti-natural" de la lucha de clases, "confundiendo la justicia con la igualdad absoluta" (idem, s.p.). Para el gremialismo, la crisis estructural, política y económica por la que atraviesa Chile durante los años 1970 poco tiene que ver con una problemática materialista. Resulta más bien de una desviación de orden espiritual que justifica la incitación a movilizarse por la "reconstrucción moral de la nación". Notemos que este pensamiento propio de un catolicismo tradicionalista encuentra su origen en la doctrina original del partido conservador que reconocía también como núcleos de base de la sociedad la familia o las corporaciones, a diferencia de las fuerzas aglomeradas tales como las clases sociales (Pereira 1994, p. 14).

Los miembros del movimiento se distinguen por su facultad de hablar con la verdad, de encarnar un ejemplo entregándose cuerpo y alma al servicio de una "causa justa" 23 , volviéndose en resumidas cuentas elegidos entre los llamados, líderes. El movimiento gremial es por su parte presentado como:

${ }^{23}$ Esta mística del "servicio Chile se confunde con el amor de Dios es asimilada por Guzmán a una vocación al "apostolado", incluso al martirio.
“[...] un espíritu que se define como un modo de hacer las cosas. Como espíritu que es, lo importante en él no es su organización o resultados cuantitativos; lo verdaderamente importante en él son sus miembros [...] que son los únicos portadores de esta verdad. Donde exista un Gremial hay gremialismo, y hay una persona dispuesta a imponerse y hacer escuela en su modo de ser" (Movimiento Gremial, FEUC, 1972). 
${ }^{24}$ Esta "metafísica de la persona", según la expresión de Cristi (2000, p. 14 y pp. 62-63), que concibe al hombre como un ser dotado de espiritualidad, postula su primacía ontológica sobre la sociedad o el Estado. Esta mirada refleja la temprana cercanía del ideólogo con el planteamiento liberal de un estado de naturaleza.
La cohesión del movimiento depende también de las "afinidades electivas" entre sus miembros, cualidad elevada al rango de ley natural dado que la comunidad inicial es presentada como el fruto de una "unión natural y espontánea de personas ${ }^{24}$ que se definen por una misma manera de ser y de actitud frente a las cosas" (idem), como un grupo homogéneo de pares que se reconocen en la defensa de una "libertad reconquistada el 11 de septiembre de 1973" (idem).

Aunque la visión del orden social de los futuros dirigentes de la UDI encaja con estas ideas, sus habitus de clase y católico no bastan por sí solos para explicar su compromiso militante. Para entender éste, cabe en efecto tomar en consideración las modalidades bajo las cuales éstos entran en contacto con una red de reclutamiento (Passy 2003) que contribuye a reforzar su sentimiento de pertenecer a una "comunidad de destino".

\section{III.3. Reclutamiento y primeros mecanismos de socialización}

${ }^{25} \mathrm{Al}$ igual que Novoa y Longueira, ambos pertenecen al grupo de los "coroneles".

\footnotetext{
${ }^{26}$ Es en efecto lo que nos enseña la sociología de lo religioso respecto de la conversión. Según David Snow y Richard Machalek, "cuando se produce este tipo de giro, el cambio percibido por la conciencia aparece tan radical en sus efectos como si el universo discursivo fuese enteramente nuevo", cf. Snow \& Machalek (1984, p. 171).
}

Esta red de reclutamiento tiene como punto de anclaje la facultad de derecho de la Universidad Católica, donde enseña Jaime Guzmán. Al igual que este último, Jovino Novoa y Hernán Larraín cursan sus estudios superiores en esta casa de estudios antes de titularse de abogados y enseñar el derecho. En 1969-1970, Hernán Larraín ocupa también la presidencia de la FEUC.

Dentro de la segunda generación, las trayectorias universitarias y profesionales se diversifican levemente, aunque la Facultad de Derecho de la Universidad Católica se mantenga como el bastión elitario del gremialismo. Andrés Chadwick y Juan Antonio Coloma conocen a Jaime Guzmán en 1973 como alumnos de esta Facultad. Este encuentro que se transformará en una relación de "amistad" será decisivo para su futuro político, tratándose de dirigentes influyentes al interior de la UDI ${ }^{25}$. Ambos ocuparán a su vez sucesivamente la presidencia de la FEUC.

Por último, dos de los presidentes de la UDI -Pablo Longueira y Patricio Melero- cursan sus estudios superiores en la Universidad de Chile, donde se hacen notar por sus dotes de organización, y son invitados a armar un movimiento estudiantil que replicara el modelo del gremialismo de la Universidad Católica. En 1977, Melero se convierte en vice-presidente de la Federación de los Centros de estudiantes de la Universidad de Chile (FECECH). En cuanto a Pablo Longueira, tras haber sido un tiempo vetado por el ideólogo por no pertenecer al gremialismo (Longueira 2003, p. 87), obtiene la presidencia de la FECECH en 1981. Como el mismo lo relata, Jaime Guzmán es quien redacta su discurso de investidura (Longueira 2003, p. 88). Durante los años ochenta, Longueira empieza, por su parte, a entablar una relación de "profunda amistad" con Guzmán, quien le da un rol clave en la implantación del movimiento en los barrios populares.

Este trabajo de reclutamiento, incluso de "conversión", entendiendo ésta como una revelación del individuo a sí mismo y no como una ruptura biográ fica $^{26}$, tiene lugar paulatinamente, lo que refuerza probablemente la percepción del movimiento como "unión natural" de personas o la de "nunca haber sido otra cosa" que UDI -según las palabras de uno de nuestros entrevistados-, a pesar de un pasado de simpatizante centrista o de izquierda. El ejemplo más llamativo de esta conversión es sin duda el de Andrés Chadwick, inicialmente afligido por el golpe de Estado debido a sus afinidades políticas ${ }^{27}$. Requerirá de cuatro años y numerosos intercambios con Jaime Guzmán para adoptar su proyecto político.

“A mediados del año 1977, recuerdo como si fuera ayer, un domingo tarde llamé 
${ }^{27}$ Chadwick se vuelve simpatizante del Movimiento de Acción Popular Unitaria (MAPU), ala izquierda de la DC que se escinde de ésta en 1969, a principios de los años setenta, siguiendo los pasos de su cuñado José Antonio Viera-Gallo, quien es entonces dirigente del MAPU y sub-secretario de Justicia del gobierno Allende. Éste es obligado al exilio después del golpe de Estado. encontraba sentido a no ser parte de lo que él estaba formando a través del Movimiento Gremial, 'creo que ya no tengo nada que seguir discutiéndote en los principios y las ideas, mis diferencias son cada vez menores', concluí. Me respondió que conversáramos el lunes. Al día siguiente me dijo que me pedía un favor: que nunca olvidara lo que yo había sido porque él creía que para mí eso era algo muy importante y que me sintiera parte de lo 'nuestro' como si hubiere estado desde la primera hora" (Chadwick Piñera en Longueira 2003, p. 65).

Este deslizamiento hacia un involucramiento total no significa entonces un abandono integral de las convicciones personales para abrazar una nueva visión del mundo. Da más bien cuenta de la emergencia de un marco interpretativo en el que se integran ciertas disposiciones (habitus de clase y católico) y una socialización política (conciencia social y "vocación de servicio" forjadas en el transcurso de los años sesenta). Como muestra el relato de Chadwick relativo a su "transformación", los jóvenes gremialistas canalizan su conciencia social en un proyecto percibido como "distinto", en particular por recoger esa preocupación social:

"Yo creo que mi transformación viene por una parte de mirar lo que fue el mundo de la UP y el mundo de la izquierda en Chile que quedó demente, con el gobierno militar y no estando mis referentes en Chile... sentirme muy solo frente a esa situación, y al mismo tiempo conocer una persona como Jaime Guzmán que me cambió un poco el esquema, porque era alguien de derecha pero con una sensibilidad totalmente distinta a la derecha tradicional de nuestro país [...]. Soñaba con construir una opción en Chile que fuese distinta [...], una opción popular, por los pobres, con una perspectiva de testimonio muy fuerte [...]" (Entrevista con Andrés Chadwick, 30 mayo 2006).

\section{Extensión de la red, fábrica de una cultura institucional}

${ }^{28}$ Entrevista con Carlos Frontaura, Fundación Jaime Guzmán, 18 mayo 2006.

\footnotetext{
${ }^{29}$ Programa de debate político organizado por la UC entre 1969 y 1973.
}

Después del golpe de Estado, la forma que adopta el movimiento debe mucho a la participación de sus miembros en diferentes "espacios de reflexión o de movilización" 28 entre los cuales conviene distinguir, por una parte, las instituciones controladas por el gremialismo de las que lo son por el gobierno de Pinochet; por otra parte, los tipos de involucramiento observados que dan cuenta de roles a veces claramente diferenciados desde los cuales los actores habitan y "hacen hablar" el movimiento.

El rol de ideólogos recae principalmente en los gremialistas de la primera generación que ejercen sea una influencia directa sobre los militares, sea un liderazgo de opinión, o ambos. Es en particular el caso de Jaime Guzmán, sucesivamente miembro de las comisiones de Estudios para la Nueva Constitución (1973-1980) y de las Leyes Orgánicas Constitucionales (19831989). Éste despliega además una fuerte presencia mediática, desde el programa de televisión donde salta a la fama ${ }^{29}$, hasta sus múltiples intervenciones radiofónicas y en la prensa. El mundo universitario constituye también un espacio privilegiado de difusión de las ideas del movimiento. Como vimos, los altos dirigentes de la UDI han estudiado el Derecho en la Universidad Católica y enseñan en esta Casa de estudios. Teniendo apenas unos treinta años, Hernán Larraín se desempeña como su vicerrector de comunicación (1976-1979) y vicerrector académico (1979-1986), posiciones desde las cuales contribuye a acrecentar la influencia del gremialismo en la UC.

Los dirigentes de la segunda generación, por su parte, se dedican principalmente a la organización del movimiento y al trabajo de proselitismo en terreno. Fundan en 1975 el Frente Juvenil, cuya misión es mantener el vínculo con los dirigentes universitarios menores de treinta años, una vez concluidos sus estudios. Según uno de nuestros entrevistados, se trata de una organización "de batalla, de terreno, de las poblaciones [...]" que va a ser sucesivamente dirigida por Juan Antonio Coloma y Andrés Chadwick. En 1979, en un clima de 
especulaciones sobre el restablecimiento de la democracia, surge el grupo Nueva Democracia como un espacio de participación destinado a los profesionales mayores de 30 años. A diferencia del Frente Juvenil, este grupo busca ejercer un liderazgo de opinión, con miras al proceso institucional pronto a iniciarse.

A principios de los años 80 , cuando la crisis económica y las movilizaciones obligan el régimen a la apertura, el movimiento busca institucionalizarse dotándose de un sello popular. Se ramifica entonces hacia los barrios populares. La legitimación aparece como una dimensión importante de la iniciativa, aunque la idea de una "nueva derecha" "comprometida con el mundo de la pobreza", o que no sólo represente los intereses de la clase dominante, figure en el proyecto inicial. Fruto de un involucramiento militante intenso, el departamento poblacional se arma así en un año, adoptando como estructura de base el comité, y articulándose con departamentos juvenil y profesional (Soto 2001). Son reclutados los primeros cuadros de orígen popular y fichados los primeros adherentes durante reuniones en las que entran en contacto con los dirigentes de la UDI, se familiarizan con su doctrina y escuchan hablar, según Pablo Longueira, de "las virtudes de la economía social de mercado para los pobres" (Entrevista con Pablo Longueira, 6 de septiembre de 2007).

La expansión de la red depende así de la articulación entre el gremialismo y los grupos que éste controla, pero también de ciertas instituciones del régimen militar, tales como la Secretaría de la Juventud que sostiene política y económicamente el Frente Juvenil. Éste es creado tras el golpe de Estado y saca provecho de la mística y eficacia gremialistas, como demuestra el hecho de que en 1975, el gobierno se felicite de la presencia en el 70\% de las comunas del país de este órgano de movilización que tiene por objetivo "transformar el apoyo juvenil en un elemento que dé vigor intelectual al régimen y acentúe el carácter activista de la reconstrucción nacional" (Huneeus 2000, p. 359). El gremialismo se instala de esta forma en el rol que recayó en los partidos de gobierno creados por los militares en otros contextos latinoamericanos (Skidmore 1988). Entre los principales dirigentes de la UDI, sólo Patricio Melero asume la dirección de la Secretaría entre 1982 y 1985 (tiene entonces veintiséis años), antes de ser

${ }^{30}$ Esta etapa profesional es calificada por el dirigente como "muy realizadora", tanto del punto de vista del rol ejecutivo y de primer plano que le confirió como del ejercicio de una "vocación social" vivida bajo la modalidad del don de sí mismo (Entrevista con Patricio Melero, 16 de marzo de 2006).

${ }^{31}$ Para comprender la colusión entre los Chicago Boys y los pioneros de la teoría económica de la Escuela de Chicago, remitimos al libro de Yves Dezalay y Bryant G. Garth (2002).

${ }^{32}$ El primer presidente de la UDI, Julio Dittborn, ocupa el puesto de sub-director nacional de ODEPLAN hasta 1983, sucediendo en el cargo a Miguel Kast, notorio gremialista y Chicago boy quien había sido su profesor designado alcalde de la comuna popular de Pudahuel $^{30}$, posición desde la cual contribuye al anclaje local del partido.

Por último, un tercer grupo, el de los economistas formados en la Universidad de Chicago, se encarga de poner en marcha las estructuras de la nueva economía, jugando un rol fundamental en la legitimación tecnocrática del gobierno (Silva 1991, p. 395). Trabajan en la Oficina de Planificación nacional (ODEPLAN), inicialmente fundada en 1967 bajo la presidencia de Frei Montalva, como un órgano de consejo en materia de planificación económica y social. Durante el régimen militar, esta oficina contribuirá a la implementación de un programa de privatización y reducción del déficit fiscal, en el marco del cual son por primera vez probadas a escala de un país las tesis de Milton Friedman ${ }^{31}$. Después del golpe de Estado, el gremialismo abandona así progresivamente su orientación corporativista para adherir a la doctrina neoliberal, de lo que da cuenta el lugar ocupado por los "Chicago Boys" al interior del movimiento ${ }^{32}$.

Las trayectorias de los dirigentes de la UDI revelan entonces primero una circulación de un espacio a otro, lo que les permite acumular diferentes tipos de recursos, desde la extensión de su capital social hasta la adquisición de un "capital militante" (Matonti \& Poupeau 2004). Reinvierten en particular en el Frente Juvenil los saberes activistas acumulados en la Universidad, y adquieren en él nuevas competencias, a su vez aprovechadas en la Secretaría de la Juventud. Las reglas de reclutamiento y pertenencia que adopta la agrupación a medida que se extiende deben igualmente mucho a los vasos comunicantes que se 
en el Instituto de Economía de la UC. Kast se había unido por su parte a la ODEPLAN en 1973, preocupado de dar un rostro humano al modelo neoliberal.
${ }^{33}$ Brazo armado del partido comunista en la lucha contra el régimen militar, el FPMR es fundado en 1983 adoptando el nombre del héroe de la Independencia chilena, Manuel Rodríguez. En septiembre de 1986, la organización intenta también asesinar al general Pinochet. ${ }^{34}$ Cf. el discurso de Jaime Guzmán en el funeral de Simón Yévenes (Guzmán 1986).

35 Jaime Guzmán declara al respecto en el diario $E l$ Mercurio del 20 mar 1988: "Nuestro sector se caracteriza por la homogeneidad de todos sus integrantes y dirigentes". establecen entre los diferentes espacios e instituciones analizados, mediante la "multiposicionalidad" (Boltanski 1973) de los actores. Éstos importan en efecto en la organización saberes, un saber hacer y valores y, por un efecto de retroalimentación, se reconocen en la estructura autoritaria que ésta adopta, hasta la promueven. De esta manera, sus conductas empiezan a ser determinadas duraderamente por su pertenencia. Particularmente en el caso de los funcionarios cuyos superiores jerárquicos son militares, el hecho de ser socializados por una institución coercitiva contribuye a la cristalización de un perfil de líder-tipo: disciplinado (es decir, no "conflictivo"), eficaz (aliando talento organizacional y capacidad de trabajo - Pinto 2006, pp. 75-76), y patriota (capaz de mirar más allá de sus ambiciones personales).

Bajo el régimen militar, la agrupación afinitaria evoluciona así en una red fuertemente regulada donde se ha precisado una division del trabajo militante en particular a través de la cristalización de nuevos roles -, junto con cierto perfil de dirigente. La expansión del movimiento inicial se realiza además en el contexto de una "nación de enemigos" (Constable \& Valenzuela 1991) segmentada. En 1986 y 1991, respectivamente, son asesinados Simón Yévenes, presidente de una asociación de comerciantes de una comuna popular y férreo opositor al partido comunista y Jaime Guzmán, dos atentados perpetrados por el Frente Patriótico Manuel Rodríguez (FPMR) ${ }^{33}$. Mientras la violencia política contribuye a exacerbar la clausura de la comunidad sobre sí misma, la UDI es fundada en 1988, contando con un "mártir" con un "testimonio heroico" 34 . La disciplina constituye uno de los principios básicos del partido ${ }^{35}$, dando cuerpo a una cultura institucional hecha de valores y de representaciones que orientan conductas y prácticas comunes (Biland 2011, p. 178), y de cuya apropiación por las futuras generaciones dependerá que encajen o no con ella.

¿Cómo logra permanecer en el tiempo y crecer este partido luego del deceso de su principal líder y tras la vuelta a un régimen democrático? ¿Cómo se adapta a las nuevas reglas del juego político? En la última parte de este artículo, estas preguntas nos conducirán a interesarnos por los mecanismos de la reproducción de la UDI y por las modalidades de la consolidación de su cultura institucional, sin por ello suscribir la tesis de la institución monolítica. En efecto, la relación partidista inicial (que adopta la forma de la "comunidad") evoluciona hacia otra relación (la "sociedad" que apunta a la defensa del statu quo económicoinstitucional). Mostraremos que esta evolución no corresponde al tránsito de un estado de la agrupación a otro, sino que se traduce por la yuxtaposición de dos concepciones competitivas de la verdad y de la legitimidad institucional (cf. Anexo 2) que van a ser objeto de usos diferenciados, a medida que se incorporan al partido nuevas generaciones de dirigentes. Estas disputas en torno a la identidad de la UDI serán analizadas a la luz de los perfiles sociográficos y trayectorias de los nuevos entrantes.

\section{Dinámicas y modalidades de la reproducción partidista}

El asesinato de Jaime Guzmán cataliza una reconfiguración del aparato partidista en torno a una dirección colegial. En 1989, Julio Dittborn asume la presidencia de la UDI, confiriéndole una imagen legitimadora más técnica que política. Sin embargo, tras el asesinato del ideólogo, Jovino Novoa es quien se impone como la figura de mayor consenso para asegurar el relevo, habida cuenta de su cercanía con Guzmán, pero también de su sensibilidad religiosa que contrasta con el perfil liberal de Dittborn (Pollack 1999, p. 161). Bajo su conducción, la UDI conoce un crecimiento electoral sostenido, pasando del 9,8\% de los votos en la elección legislativa de 1989 (11 diputados) a 14,5\% en 1997 (17 diputados). Liderado por Pablo Longueira a partir de 1998, el partido se convierte en la primera fuerza política de Chile logrando casi la victoria en la 
${ }^{36}$ Para ser electo, un alcalde tiene que obtener la mayoría absoluta de los sufragios, cuando un candidato al Parlamento sólo requiere el $33,4 \%$. La distorsión se vuelve aún más patente en el caso de comunas que corresponden a distritos parlamentarios.

\footnotetext{
${ }^{37}$ La encuesta sociográfica que utilizamos fue autoadministrada a 111 delegados de la UDI durante uno de sus Consejos generales, los días 14 y 15 de diciembre de 2007. Aunque la tasa de respuesta haya sido superior al $50 \%$, dos sesgos merecen ser
}

elección presidencial del año 2000, con Joaquín Lavín de candidato, y eligiendo a 31 diputados en 2005 .

Beneficiándose de los efectos del sistema binominal, del éxodo hacia la derecha de los votantes centristas, de la función cohesionadora y disciplinaria ligada a la "homogeneidad cultural" de sus parlamentarios (Joignant \& Navia 2003), pero también por lograr desplegar exitosamente una estrategia dual de penetración electoral tanto en los sectores altos como bajos (Luna 2010); la UDI se consolida como el primer partido de Chile. En 2009, controla un tercio de la Cámara baja y posee la bancada más numerosa (39 diputados).

Este fenómeno de crecimiento va a suscitar debates internos en torno al proyecto de la agrupación. Mientras algunos dirigentes opinan que ésta debe conservar primordialmente su capacidad de influencia política -mediante el control del poder legislativo-, otros prefieren aumentar su capacidad representativa con miras al control del Ejecutivo. Estas posiciones contrastadas tienden a exacerbarse cuando la doctrina parece amenazada por el crecimiento de la organización o en los momentos de crisis de liderazgo, lo que ocurre en 2006 cuando cae el nivel de popularidad de Joaquín Lavín, en medio de su segunda postulación a la presidencia de la República. El debate en torno "al alma de la UDI" se reactiva entonces, de lo que dan cuenta las declaraciones de un cercano colaborador de Jaime Guzmán, quien recuerda que "[inicialmente] éste no era un partido electoralista, sino una escuela para formar gente en el servicio público [...]", fundada en "el testimonio de nuestras convicciones aun cuando fuera impopular" y debiendo desde luego preservar su carácter "monolítico" (Cordero 2008). En 2006, el grupo de los ediles se queja también de no incidir lo suficiente en las decisiones internas, a diferencia de los diputados cuyo peso electoral es a veces menor, pero quienes garantizan en mayor medida la defensa de la agenda valórica ${ }^{36}$. Levantan entonces la bandera de la democratización interna del partido. Diferentes actores o grupos de actores se encuentran así implicados en esas luchas tanto generacionales como posicionales: los "ideólogos" de la comunidad de origen y los "hombres de terreno" que hicieron prosperar la organización, los ediles que cumplen un papel ejecutivo y los diputados, por último los altos dirigentes de la segunda generación y los parlamentarios de generaciones posteriores. Estos últimos no dudan en sublevarse cuando estiman que se transige con los valores para fines electorales y denuncian también la ausencia de democracia interna.

El argumento del necesario regreso a las "raíces" del partido, a un sistema de relaciones estables cercano a la comunidad moral que privilegiaba la influencia sobre las ideas, alimenta así los debates internos, al igual que las estrategias de posicionamiento de ciertos actores o grupos de actores. Detrás de esos usos diferenciados de la institución, el análisis sociográfico cruzado con el de las trayectorias, permite objetivar la existencia de grupos cuyas propiedades sociales y experiencias socializadoras difieren. Una encuesta aplicada en 2007 a los delegados de la UDI deja así entrever la existencia de tres cohortes: la de los cuadros más jóvenes (menores de 40 años), varios de los cuales no habían nacido al momento del golpe de Estado, un grupo etario intermedio (40-49 años) y la cohorte de los altos dirigentes socializados políticamente durante el régimen militar (la cual agrupa a los miembros de las primera y segunda generaciones de 50 años y más $)^{37}$.

Los cuadros de la primera cohorte se caracterizan por su socialización secundaria en establecimientos religiosos (principalmente católicos) y privados, por poseer estudios universitarios $(60,7 \%)$ y haberlos cursado en instituciones privadas no tradicionales que conocen un boom a fines de los años 80 . Algunas de ellas son ligadas a movimientos apostólicos tales como los Legionarios de Cristo, el Opus Dei o Schoenstatt, lo que constituye una primera 
señalados: la asistencia a ese Congreso general fue relativamente baja (aproximadamente el $40 \%$ de los 800 delegados con que cuenta la UDI), con una sobre-representación de pre-candidatos en la elección municipal de 2008 diferencia respecto a la segunda generación de dirigentes (50 años y +), sensibilizados a la cuestión social en el contexto de una Iglesia reformada. Los integrantes de las dos primeras cohortes comparten además un capital cultural más alto que los mayores, dado que aproximadamente un tercio posee estudios de postgrado. Este capital es detenido en particular por los dirigentes menores de cuarenta años, dos tercios de los cuales hicieron estudios universitarios (Tabla 1). Es en este sentido probable que la elevación del nivel de estudios de una generación a otra contribuya a modificar el posicionamiento, las representaciones y las aspiraciones de quienes pretenden reivindicar recursos políticos.

Esta tendencia es congruente con el examen de la profesión. Los delegados menores de 40 años se reparten equilibradamente entre el sector privado y público de la economía, mostrando sin embargo una mayor propensión a trabajar en el primero. Puede tratarse de las generaciones que en 2007 dudaban entre la política y la posibilidad de tener una actividad profesional más lucrativa e independiente del partido. Detentores de un mayor nivel educacional, estos individuos pueden también reclamarse de una identidad profesional a menudo consolidada, la cual no debe nada a la UDI, y les lleva más bien a esperar que "el juego valga la apuesta". En cambio, no es el caso de los cuadros de la cohorte intermedia, entre los cuales cerca del $50 \%$ son funcionarios públicos y trabajaban probablemente en las municipalidades controladas por la UDI. Entre los delegados de más edad figura un número importante de individuos que ocupaban cargos de elección popular y muy pocos empleados del sector privado.

Por último, la casi-totalidad de los delegados se declara creyente, cifra que alcanza el $100 \%$ entre los más jóvenes. En cambio, la primera cohorte se distingue de las demás por su grado de práctica religiosa. En efecto, el 86,2\% de sus integrantes se considera bastante o muy religioso. El primer grupo etario transita así de una instancia de socialización católica a otra (escuela, colegio, Universidad, Iglesia), lo que sucede en menor medida para los cuadros de más edad y menos aún para la cohorte del medio. En este último caso, ello podría indicar un relajamiento de la selección a raíz del crecimiento del partido, que afecta en particular a los ediles o consejeros municipales cuya investidura responde a menudo a un cálculo electoral y a recursos de implantación local.

Tabla 1 - Variables sociales, según tramos de edad

\begin{tabular}{|c|c|c|c|}
\hline & - de 40 años \% & 40-49 años \% & 50 años y $+\%$ \\
\hline \multicolumn{4}{|l|}{ Educación } \\
\hline $\begin{array}{l}\text { E. Básica en establecimientos particulares } \\
\text { pagados religiosos }\end{array}$ & 52 & 21,9 & 39,5 \\
\hline Poseen estudios universitarios & 60,7 & 41,2 & 48,7 \\
\hline Estudiaron en U. Privada No Tradicional & 75 & 35,5 & 15,2 \\
\hline Poseen estudios de postgrado & 28,6 & 29,4 & 17,9 \\
\hline \multicolumn{4}{|l|}{ Religión } \\
\hline Creyentes & 100 & 94,3 & 95,6 \\
\hline Son católicos & 96,6 & 87,5 & 95,2 \\
\hline Son bastante o muy religiosos & 86,2 & 69,7 & 72,1 \\
\hline \multicolumn{4}{|l|}{ Profesión } \\
\hline Trabajan en el sector público & 31,6 & 48,3 & 36,4 \\
\hline Trabajan en el sector privado & 36,8 & 24,1 & 15,2 \\
\hline $\mathrm{N}$ & 29 & 37 & 45 \\
\hline
\end{tabular}

Fuente: Elaboración propia en base a los resultados de las encuestas FONDECYT N 1061034 y VID SOC07/29-02. 
Estos resultados indican también que las redes de la UDI se han diversificado y que diferentes instituciones convergentes o conexas concurren ya directamente a la homogeneización moral de los futuros cuadros partidistas, reforzándose (Alenda \& Sepúlveda 2009, p. 166). Aquello sugiere que los habitus de los actores en cuestión contribuyen a reforzar ciertas características institucionales debido a la homología entre las cualidades valorizadas (disciplina, sentido tanto de la jerarquía como de los valores) en ambos universos religioso y partidista. Por lo demás, este esfuerzo de homogeneización pasa a ser asumido por el partido mediante la implementación progresiva de instituciones internas que contribuyen a reforzar la cultura institucional (Tabla 2).

A partir de los años 1990, la Juventud UDI adquiere en efecto una importancia creciente. Entre los delegados menores de 40 años, el 82,1\% declara haber sido parte de ella contra un $36,1 \%$ de la cohorte siguiente y sólo el 4,9\% del último tramo. La participación en actividades con la Juventud del partido es también mayor para los cuadros más jóvenes. Se observa en cambio que los miembros de los dos primeros tramos han recibido una formación política entregada por el partido, a diferencia de los de más edad formados bajo el régimen militar. En efecto, cerca de un tercio de los delegados de 40-49 años declara haber participado en escuelas de formación o de liderazgo. Entre los más jóvenes, si bien sólo un 22,2\% ha recibido una formación en una Escuela de liderazgo, un $37 \%$ tuvo una preparación política.

Desde 1991, esta formación, al igual que la transmisión de la cultura institucional, recae también en la Fundación Jaime Guzmán (FJG) cuya misión consiste en difundir el pensamiento del ideólogo (incluso en las comunas populares mediante seminarios) pero también en perpetuar su obra, canalizando o despertando "vocaciones de servicio público". La FJG opera además como una instancia de inserción profesional. Aunque un cierto número de jóvenes gremialistas que trabajan en ella no sientan la necesidad de convertir su compromiso social en adhesión política, contribuyen a reforzar la estructura territorial de la colectividad al iniciar su vida laboral en los municipios ganados por ésta (en particular en las comunas populares), o adquiriendo una primera experiencia profesional como asesores parlamentarios. Otros siguen colaborando con la FJG (dando charlas o haciendo clases), paralelamente a los cargos que ocupan a veces en la Juventud UDI. En varios casos, el aprendizaje de los mecanismos y estrategias de las campañas electorales se realiza también en EE.UU. en el Leadership Institute, órgano de formación y colocación profesional de los cuadros del partido Republicano ${ }^{38}$. En este sentido, la UDI opera como una red de promoción abierta a sus miembros más comprometidos y promisorios.

En síntesis, la comparación de estos tres grupos pone en evidencia un perfil de cuadro joven muy apegado a los valores religiosos y dotado de capitales fuertemente valorados al interior de la agrupación, los cuales se acumulan y

Tabla 2 - Acciones realizadas antes o durante la militancia en la UDI, según tramos de edad (\% de respuestas “Sî́)

\begin{tabular}{lccc}
\hline & - de 40 años $\%$ & $40-49$ años $\%$ & 50 años y+\% \\
\hline Pertenencia a la Juventud UDI & 82,1 & 36,1 & 4,9 \\
Trabajos con la Juventud UDI & 29,6 & 16,7 & 2,4 \\
Participación escuelas de formación & 37 & 33,3 & 17,1 \\
Participación escuelas de liderazgo & 22,2 & 30,6 & 7,3 \\
N & 27 & 36 & 42 \\
\hline
\end{tabular}

Fuente: Elaboración propia en base a los resultados de las encuestas FONDECYT N ${ }^{\circ} 1061034$ y VID SOC07/29-02. 
cual está asociada el partido republicano (PR) debido a su pertenencia a la Unión Internacional Demócrata (IDU), de la cual la UPLA es la rama regional.

39 Según nuestra encuesta, el $58,6 \%$ de los delegados menores de 40 años participa en agrupaciones religiosas: el Opus Dei, los Legionarios de Cristo o Schoenstatt. potencian: una socialización secundaria religiosa, una fuerte práctica religiosa y la pertenencia a redes religiosas ${ }^{39}$. Los delegados más jóvenes cuentan también con un capital cultural superior al de sus pares de más edad. Por último, la preparación política que reciben depende principalmente de la UDI. Estos resultados hacen depender la homogeneización partidista de dos procesos. El primero tiene su origen en la institución y las instancias internas y externas que van apareciendo a lo largo del proceso de institucionalización: la FJG cuyo directorio está integrado por cuatro de los más altos dirigentes de la UDI concurre en este sentido a la fábrica y a la reproducción de un "líder-tipo" muy competitivo. El segundo depende más bien de las redes de reclutamiento de la UDI, principalmente religiosas y universitarias. Las características sociales y la formación política recibida por los delegados más jóvenes dejan al respecto entrever un reajuste de la institución sobre un perfil de cuadro fiel a los valores originales del gremialismo, lo que confirma la comparación con el perfil biográfico de los candidatos a la elección parlamentaria de 2009, seleccionados entre las "nuevas generaciones" del partido (tienen entonces entre 28 y 36 años, cf. Tabla 3).

La Facultad de Derecho de la Universidad Católica sigue siendo el principal foco de reclutamiento. Siete candidatos de doce estudiaron en ella. La mayoría hace ahí sus primeras armas como líderes estudiantiles, al igual que los primeros gremialistas. Conforme a la tendencia observada en nuestra encuesta, el grueso posee estudios de postgrado y se corrobora también el vínculo sistemático con la FJG donde la casi-totalidad ha perfeccionado sus habilidades dirigenciales, inicialmente puestas en práctica, en muchos casos, en el marco del movimiento gremial. Por último, la política es al menos en parte heredada para varios de estos jóvenes: Juan Antonio Coloma A. es el hijo del senador del mismo nombre, Cristóbal Leturia el de uno de los primeros dirigentes del movimiento gremial, Enrique Van Rysselberghe es hermano de la dirigenta y ex alcaldesa de Concepción Jacqueline Van Rysselberghe (2000-2010), Francisco Moreno Guzmán es sobrino de Jaime Guzmán, etc.

Tabla 3 - Perfil biográfico de los candidatos a la elección parlamentaria de 2009

\begin{tabular}{|c|c|c|c|c|c|c|}
\hline & $\begin{array}{c}\text { Estudios } \\
\text { universitarios } \\
\text { (Pontificia } \\
\text { Universidad } \\
\text { Católica) }\end{array}$ & $\begin{array}{c}\text { Vínculo(s) } \\
\text { Fundación Jaime } \\
\text { Guzmán }\end{array}$ & $\begin{array}{c}\text { Dirigente } \\
\text { Juventud } \\
\text { UDI }\end{array}$ & Concejal/a & $\begin{array}{l}\text { Diputado/a } \\
2010-2014\end{array}$ & $\begin{array}{c}\text { Actualmente } \\
\text { funcionario } \\
\text { ministerial } \\
\text { (cargo de } \\
\text { confianza) }\end{array}$ \\
\hline Giovanni Calderón & $*$ & & & & $*$ & \\
\hline Juan Antonio Coloma A. & $*$ & $*$ & $*$ & & & $*$ \\
\hline María José Hoffmann & & $*$ & $*$ & $*$ & $*$ & \\
\hline Cristóbal Leturia & & $*$ & & & & $*$ \\
\hline Javier Macaya & $*$ & $*$ & & & $*$ & \\
\hline Francisco Moreno & $*$ & $*$ & & & & $*$ \\
\hline María Paz Oyarzún & $*$ & $*$ & $*$ & & & $*$ \\
\hline Marcelo Rojas & & $*$ & $*$ & & & $*$ \\
\hline Ernesto Silva & $*$ & $*$ & $*$ & & $*$ & \\
\hline Arturo Squella & $*$ & $*$ & * & & $*$ & \\
\hline José Luis Uriarte & & * & $*$ & & & $*$ \\
\hline E. Van Rysselberghe & & $*$ & & $*$ & $*$ & \\
\hline
\end{tabular}

Fuente: Elaboración propia en base a archivos de prensa. 
Volvemos a encontrar diferentes fenómenos previamente observados en las trayectorias de los dirigentes de más edad, tales como su multiposicionalidad. En efecto, estas nuevas élites comparten a veces su tiempo entre el partido, como dirigentes de la Juventud, y la FJG. Circulan también entre diferentes espacios de reclutamiento y de formación (el mundo local, el parlamento...) por medio de la FJG. Por último, capitalizan esos aprendizajes sucesivos: la mitad llega al Parlamento; la otra mitad se convierte en altos funcionarios. El examen del reclutamiento y de la selección de candidatos confirma así, por un lado, la consolidación de la UDI-empresa doctrinaria. Pero por el otro, tanto las características sociográficas como los capitales acumulativos de los dirigentes más jóvenes permiten aclarar lo que aparece de buenas a primeras como "conflictos generacionales". Como vimos, éstos son el fruto de socializaciones y representaciones diferenciadas que modifican inevitablemente la relación con la institución, al suscitar ambiciones legítimas.

Sin embargo, la institución supo responder a esas ambiciones de poder, con una flexibilidad que invita a cuestionar la tesis defendida por Levitsky, según la cual la rutinización afectaría la estabilidad estratégica de un partido en cuanto a su capacidad de renovación de liderazgos (Levistsky 2003, p. 19). En efecto, desde su creación, el gremialismo tuvo como característica abrir a sus jóvenes miembros el acceso a importantes posiciones de poder. La UDI-sociedad no contraviene la regla, lo que refleja el perfil etario de los candidatos en las elecciones legislativas de 2005 y 2009. En esta última, un poco más de un tercio tenía menos de cuarenta año mientras en 2005, esta proporción ya se acercaba al tercio. Nuestra encuesta muestra también que un sistema de gratificaciones progresivas concurre a la fidelización de los miembros más "meritorios", así como a la renovación generacional, en un partido que demuestra una capacidad real de "garantizar la movilidad de sus cuadros y ajustar la demanda y la oferta de retribuciones" (Gaxie 1977, p. 132).

De hecho, el examen del acceso de los delegados a cargos internos pone en evidencia aquello. En la Tabla 4, hemos ordenado dichos cargos en tres categorías, distinguiendo las posiciones ocupadas "alguna vez" de las que lo eran al momento de la encuesta.

Optamos por incorporar los cargos de dirigentes de la juventud nacional en la categoría "cargos medios" -cuando se trata de posiciones de mucha visibilidad, a menudo de trampolines para una carrera parlamentaria- para evitar así inflar la representación de los jóvenes (menos de 40 años) en la categoría A. Observamos que más del $80 \%$ de los delegados en general ha ejercido algún cargo alto pero que los dirigentes mayores de 50 años están sub-representados en las categorías media y baja (B y C), lo que recuerda que las reglas de promoción interna se establecen recién a fines de los años 80. En general, los delegados de más edad no alcanzan a militar en la Juventud UDI. Si consideramos el acceso a los cargos altos al momento de la encuesta (2007), se observa también que más de la mitad de los encuestados más jóvenes los ocupaba entonces $v s$. sólo el 2/5 de los cuadros de las dos cohortes siguientes.

Si bien esos cargos no entregan responsabilidades altamente valoradas por los cuadros y las retribuciones mencionadas no implican necesariamente influir en las decisiones internas, se agrega a estas gratificaciones el poder conseguir la investidura del partido para desafíos electorales más ambiciosos. Al interior de la agrupación, el mantenimiento del orden depende por lo tanto de esfuerzos de homogeneización que han sabido sacar provecho de socializaciones previas: educacionales, religiosas o políticas. Debe también mucho a la acción pedagógica de la institución que descansa en un sistema de retribuciones ajustadas a las expectativas y ofrecidas a quienes demostraron ser electoralmente rentables y encajar con el perfil de la institución. 
Tabla 4 - Cargos ocupados en la UDI, según tramos de edad

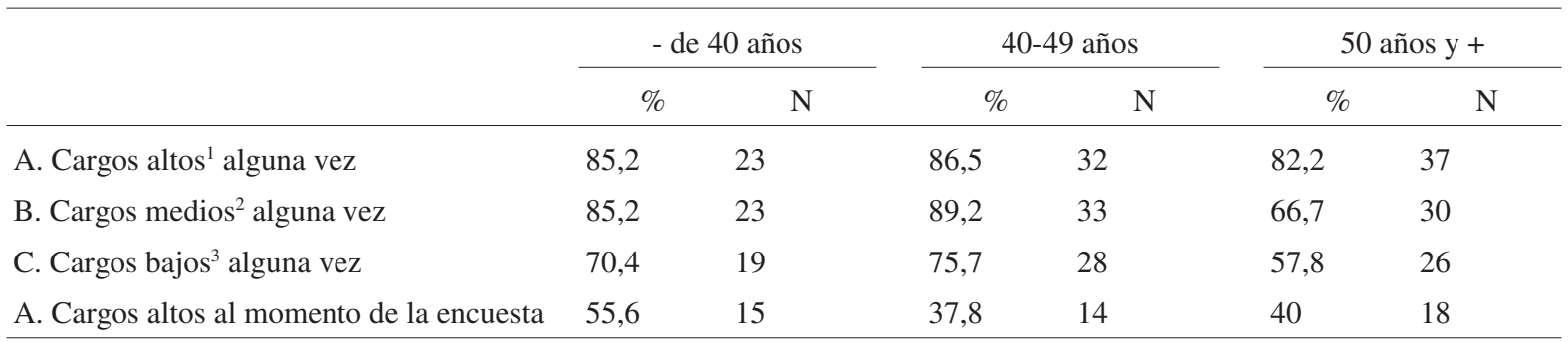

${ }^{1}$ Consejeros nacionales, miembros del Tribunal Supremo, miembros de la directiva nacional, miembros de la comisión política ${ }^{2}$ Dirigentes regionales, dirigentes de la juventud regional, dirigentes de la juventud nacional, consejeros regionales, consejeros distritales.

${ }^{3}$ Dirigentes poblacionales, dirigentes comunales, dirigentes de la juventud comunal.

Fuente: Elaboración propia en base a los resultados de las encuestas FONDECYT N 1061034 y VID SOC07/29-02.

\section{Conclusión}

${ }^{40}$ La noción de

"desinstitucionalización"

ofrece un buen ejemplo de este tipo de razonamiento propio del neo-institucionalismo.

Remite a una suerte de "patología" institucional durante la cual nuevos actores emergen cuya contestación obliga a la institución a recurrir a incentivos o a la coerción para restablecer el equilibro (cf. entre otros a Olsen 2009)
En este artículo, recurrimos a la teoría del cambio institucional gradual (Mahoney \& Thelen 2010, p. 16), para analizar la capacidad de reproducción de lo instituido al interior de la UDI y su adaptación, a nivel estratégico y estructural, a condiciones exógenas y endógenas. Para ello, consideramos tres niveles de análisis: la institución, los individuos y los eventos. Entre estos últimos, tomamos en cuenta tanto los que suelen considerarse como "críticos", fundadores o estructurantes (i.e. un cambio de régimen), como los eventos discretos o "crisis" puntuales que van marcando la trayectoria de una organización. Pudimos de este modo comprobar que una alta rutinización no constituye un impedimento para la adaptación de un partido político a determinados cambios.

Cruzando esta teoría con un enfoque sociológico sobre la institución (Lagroye \& Offerlé 2011), pudimos también comprender la "institucionalización" partidista como un proceso dinámico e interactivo, que se inicia mucho antes del acta de nacimiento oficial de un partido político y no puede por lo tanto ser asimilado a un "estado puro" o una suerte de "estado de la regla" que se adquiere, se pierde o se reconquista a través de medidas correctivas ${ }^{40}$. El estudio de esta institución exitosa permitió más bien poner en evidencia una doble dinámica de institucionalización: la adaptación a un orden institucional particular de habitus adaptados/adaptables, pero también la emergencia de procesos de desajuste/distanciamiento que aparecen a lo largo del tiempo. Por un lado, la UDI reproduce un mismo tipo de liderazgo gracias al establecimiento progresivo de mecanismos formales de homogeneización que refuerzan las disposiciones iniciales de los nuevos miembros; por el otro, la renovación generacional hace variar la relación a la institución de actores o grupos de actores quienes asignan objetivos diferentes tanto a su compromiso como al partido. Los diputados más jóvenes - quienes dirigen la UDI desde la elección interna de mayo de 2014 - comparten así el proyecto de partido a vocación gubernamental, pero se reconocen al mismo tiempo en el modelo de la comunidad. Sus socializaciones educacionales y profesionales los distinguen también de los dirigentes de más edad, al igual que su distanciamiento más marcado con respecto al régimen militar, o el hecho de haber incorporado el sentido de la competencia propio de cualquier cultura partidista. Los alcaldes, por su lado, están más proclives a transar con los principios morales y más abiertos a las reformas tendientes a modificar el statu quo. Ponen de realce su compromiso social y una vocación inspirada en la labor del ex alcalde Joaquín Lavín o en el trabajo en los barrios populares de Pablo Longueira. Si la UDI logra entonces conservar su carácter de "institución fuerte" pese a esas 
tensiones internas tanto generacionales como posicionales, es gracias a su capacidad de alimentar un sentimiento subjetivo de pertenencia a un "Nosotros" (registro de la comunidad), paralelamente a lógicas de competencia propias del registro de la sociedad.

Stéphanie Alenda (salenda@unab.cl) é Doutora em Sociologia pela Universidad de Lille 1 (França) e diretora da Escuela de Sociología, Facultad de Humanidades y Ciencias Sociales, Universidad Andres Bello (República 276, Santiago Centro, Chile).

\section{Referencias}

Alenda, S.; Sepúlveda, J.I. 2009. Pensar el cambio en las organizaciones partidistas: perfiles dirigenciales y trayectorias de moderación en la Concertación y la Alianza. In: SEGPRES. Economía, Instituciones y Política en Chile. Serie Estudios. V. IV. Santiago.

Aït-Aoudia, M.; Dézé, A. 2011. Contribution à une approche sociologique de la genèse partisane. Une analyse du front national, du movimento sociale italiano et du front islamique de salut. Revue Francaise de Science Politique, 61(4), pp. 631-657.

Biland, E. 2011. Les cultures d'institution. In J. Lagroye; M. Offerlé, eds. Sociologie de l'institution. Paris: Belin.

Boltanski, L., 1973. L'espace positionnel: multiplicité des positions institutionnelles et habitus de classe. Revue de sociologie française, 14(1), pp. 3-20.

Bourdieu, P. 1980. Le sens pratique. Paris: Les éditions de Minuit.

Cordero, L. 2008. La obsesión por el tamaño hirió el alma de la UDI. Revista Capital, 230, 13-26 jun.

Collier, R.B.; Collier, D. 1991. Framework: Critical junctures and historical legacies. In __, eds. Shaping the Political Arena, Critical Junctures, The Labor Movement and Regime Dynamics in Latin America. Princeton: Princeton University Press.

Collier, S.; Sater, W. 1999. Historia de Chile 1808-1994. Madrid: Cambridge University Press.

Constable, P.; Valenzuela, A. 1991. Chile under Pinochet: A nation of enemies. New York/London: W.W. Norton \& Co.

Cristi, R. 2000. El Pensamiento Político de Jaime Guzmán. Autoridad y Libertad. Santiago: LOM ediciones.

Cristi, R. \& Ruiz, C., 1992. El pensamiento conservador en Chile: seis ensayos. Santiago: Editorial Universitaria.

Dezalay, Y.; Garth G.B. 2002. La mondialisation des guerres de palais. La restructuration du pouvoir d'Etat en Amérique Latine, entre notables du droit et "Chicago Boys". Paris: Le Seuil.

Freidenberg, F.; Levitsky, S. 2006. Informal Institutions and Party Organization in Latin America. In G. Helmke; S. Levitsky, eds. Informal Institutions and Democracy. Lessons from Latin America. Baltimore: The Johns Hopkins University Press.

Fretel, J. 2011. Habiter l'institution. Habitus, apprentissages et langages dans les institutions partisanes. In J. Lagroye; M. Offerlé, eds. Sociologie de l'institution. Paris: Belin.

Gaxie, D. 1977. Économie des partis et rétributions du militantisme. Revue Française de Science Politique, 27(1), pp. $123-154$.

Guzmán, J. 1986. Palabras de Jaime Guzmán en el funeral de Simón Yévenes. 4 abr.

Helmke, G.; Levitsky, S. 2006. Introduction. In___, eds. Informal Institutions and Democracy. Lessons from Latin America. Baltimore: The Johns Hopkins University Press.

Huneeus, C. 2000. El régimen de Pinochet. Santiago: Editorial Sudamericana.

Jepperson, R.L. 1991. Institutions, Institutional Effects, and Institutionalism. In W.P. Walter; P. DiMaggio, eds. The New Institutionalism in Organizational Analysis. Chicago: University of Chicago Press.

Joignant, A.; Navia, P. 2003. De la política de individuos a los hombres del partido: Socialización, competencia política y penetración electoral de la UDI (1989-2001). Estudios Públicos, 89, pp. 129-171.

Kitschelt, H. 1994. The Transformation of European Social Democracy. Cambridge, UK: Cambridge University Press.

Lagroye, J.; Offerlé, M., eds. 2011. Sociologie de l'institution. París: Belin.

Levitsky, S. 2003. Transforming Labor-Based Parties in Latin America: Argentine Peronism in comparative perspective. New York: Cambridge University Press.

Levitsky, S.; Murillo, M.V. 2010. Variación en la Fortaleza institucional. Revista de Sociología, 24, pp. 31-56.

Levitsky, S.; Murillo, M.V S.d. Continuity and Change in a Weak Institutional Environment. Digit. Disponível em: http://www.learningace.com/doc/5581602/411ea464a37b0dee0f977f1dd3ddd4dc/institutionalchangememo-levitskymu rillo-final-_2_. Acesso em: $1 \mathrm{dez} 2014$.

Longueira, M.P. 2003. Mi testimonio de fe. El servicio público y el sentido del dolor. Santiago: Random house Mondadori.

Luna, J.P. 2010. Segmented Party-Voter Linkages in Latin America: The Case of the UDI. Journal of Latin American Studies, 42 , pp. $325-356$.

Mahoney, J.; Thelen, K. 2010. Explaining Institutional Change. Ambiguity, Agency, and Power. New York: Cambridge University Press, p. 1-37.

Mannheim, K. 1993. [1928]. El problema de las generaciones. Revista española de investigaciones sociológicas, 62, pp. 193-242.

Matonti, F.; Poupeau, F., 2004. Le capital militant. Essai de définition. Actes de la Recherche en Sciences Sociales, 155 , pp. 4-11.

Moulián, T. 1993. La Forja de ilusiones, el sistema de partidos 1932-1973. Santiago: Flacso. 
Navia, P., 2000. Las presidenciales de 1999 en Chile: ¿hay un nuevo electorado?. Anuario Social y Político de America Latina y el Caribe. Número 3 FLACSO y Nueva Sociedad, pp. 27-35.

Navia Patricio, 3 de octubre de 2002. ¿Dónde fueron los votos del PDC?. Working Paper presentado en el Instituto de Estudios Políticos, Universidad Nacional Andrés Bello.

North, D.C. 1990. Institutions, Institutional Change, and Economic Performance. New York: Cambridge University Press.

O’Donnell, G., 1994. Delegative Democracy. Journal of Democracy, 5(1), pp. 55-69.

Olsen, J.P. 2009. Change and Continuity: An institutional approach to institutions of democratic government. European Political Science Review, 1(1), pp. 3-32.

Panebianco, A. 1990 [1982]. Modelos de partido. Madrid: Alianza Editorial.

Passy, F. 2003. Social Networks Matter. But How? In M. Diani; D. McAdam, eds. Social Movements and Networks. New York: Oxford University Press.

Pereira, T. 1994. El Partido Conservador: 1930-1965, ideas, figuras y actitudes. Santiago: Editorial Universitaria.

Peters, G. 2003. El Nuevo institucionalismo. Teoría institucional en ciencia política. Barcelona: Editorial Gedisa.

Peters, G.; Pierre, J.; King, D.S. 2005. The Politics of Path Dependency: Political Conflict in Historical Institutionalism. The Journal of Politics, 67(4), pp. 1275-1300.

Pierson, P. 2004. Politics in Time. History, institutions, and social analysis. New Jersey: Princeton University Press.

Pinto, C.R. 2006. UDI-La Conquista de Corazones Populares (1983-1987). Santiago: Ediciones Ana Victoria Durruty.

Pollack, M. 1999. The New Right in Chile 1973-97. London: Macmillan Publishers Limited.

Silva, P. 1991. Technocrats and Politics in Chile: From the Chicago Boys to the CIEPLAN Monks. Journal of Latin American Studies, 23, pp. 385-410.

Skidmore, T. 1988. The Politics of Military Rule in Brazil, 1964-1985. Oxford: Oxford University Press.

Snow, D.A.; Machalek, R. 1984. The Sociology of Conversion. Annual Review of Sociology, 10, pp. 167-190.?

Soto, A. 2001. La irrupción de la UDI en las poblaciones 1983-1987. In Annual Meeting of the Latin American Studies Association. Washington, DC.

Soto, A. \& Fernández, M., 2002. El pensamiento politico de la derecha chilena en los '60: el Partido Nacional. Revista de Historia de Chile y América, 1(2), pp. 87-116.

Valdivia Ortiz de Zárate, V. 2008. Nacionales y gremialistas. El "parto” de la nueva derecha política chilena 1964-1973. Santiago: Ediciones LOM.

Weber, M. 1995 [1922]. Economie et société. Tome 1. París: Plon.

\section{Otras fuentes}

Archivos de la Fundación Jaime Guzmán. "Movimiento Gremial”, Federación de Estudiantes de la Universidad Católica de Chile (FEUC 1969-1972).

Declaración de principios de la UDI. 1983. El Mercurio, 24 sep.

Jaime Guzmán, Su legado humano y politico. Revista Ercilla, 10 abr.

"Movimiento Gremial", Federación de Estudiantes de la Universidad Católica de Chile (FEUC 1969-1972). Archivos de la Fundación Jaime Guzmán. Digit. 


\section{ABSTRACT}

In this article, we analyze the continuities and changes of Chile's largest party in terms of both voters and seats: the Unión Demócrata Independiente (UDI). Our analysis takes into account the first steps of the UDI as a university student movement in the late 1960s and covers through 2010, when it ceased to be an opposition party and joined the Alianza por Chile center-right coalition government. Using Mahoney and Thelen's typology (2010), we show that the UDI underwent a process of incremental change, which implied the conservation and strengthening of rules and routinized procedures, however reinterpreted by successive generations of leaders. We connect the Mahoney and Thelen approach with the insights of sociology of institution, inspired by Pierre Bourdieu's theory, showing that UDI institutionalization results from a double dynamic: the adjustment to a particular order of adapted and adaptable habitus, but also the emergence of mismatch/detachment processes occurring over time and resulting in generational and positional oppositions between different groups of actors who assign distinctive goals to their engagement and to the party. We study this double dynamic, reconstructing the evolution from an initial partisan relation which takes the form of a "community" (Weber) to "society", taking into account both exogenous and endogenous factors. This work, which relies on several types of sources (biographic interviews with most of the UDI top leaders who were part of its founding core group; a sociographic survey applied to party delegates and press archives), thus apprehends party institutionalization as a dynamic and interactive process, which begins before party official birth.

KEYWORDS: Chilean Right; Sociology of partisan institutions; Independent Democratic Union; Party institutionalization; Institutional culture. 


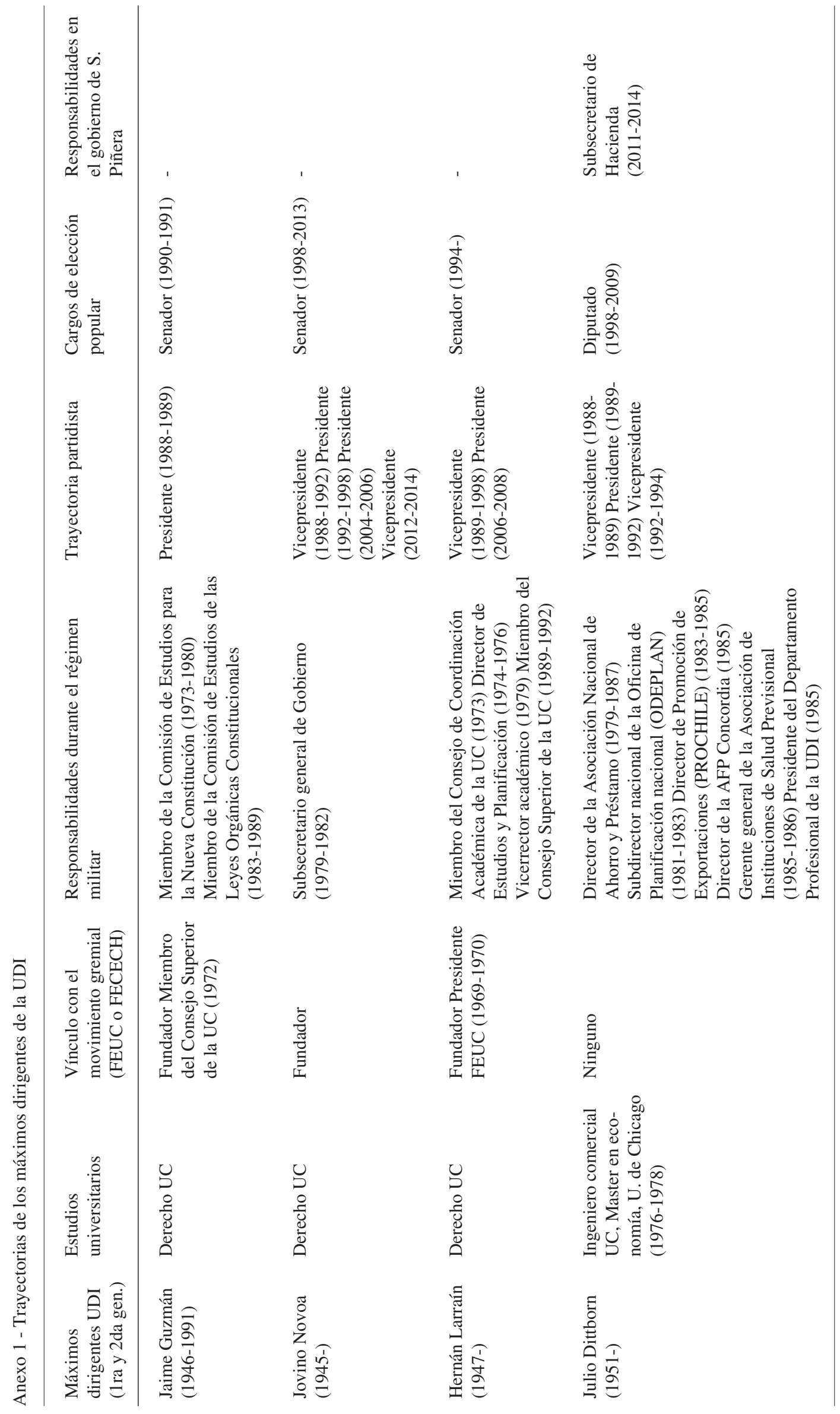




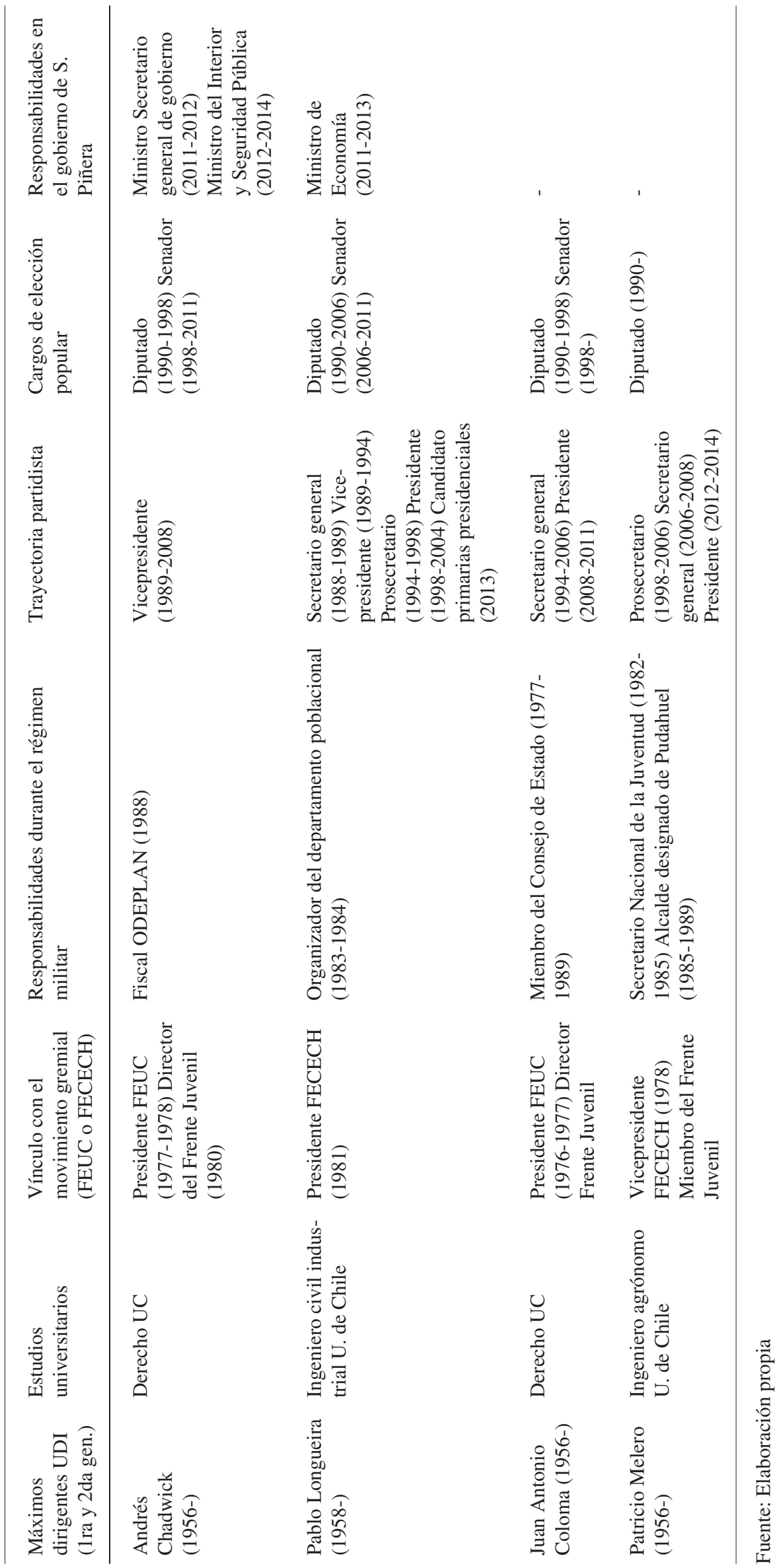


Anexo 2 - Etapas de la institucionalización partidista

\begin{tabular}{|c|c|c|}
\hline & $\begin{array}{l}\text { Modelo originario } \\
\text { Comunidad }\end{array}$ & $\begin{array}{l}\text { Institución partidista } \\
\text { Comunidad / Sociedad }\end{array}$ \\
\hline Tipo de agrupación & $\begin{array}{l}\text { Comunidad moral } \\
\text { Agrupación personalizada } \\
\text { Diferenciación de roles } \\
\text { Emergencia perfil de líder-tipo }\end{array}$ & $\begin{array}{l}\text { Comunidad moral (comunidad) } \\
\text { Partido a vocación gubernamental, dife- } \\
\text { renciación generacional (sociedad) }\end{array}$ \\
\hline Tipo de líderes & $\begin{array}{l}\text { Metafísica de la persona, régimen de } \\
\text { testimonios }\end{array}$ & $\begin{array}{l}\text { Metafísica de la persona, régimen de } \\
\text { testimonios (comunidad) } \\
\text { Líder electoralmente competitivo } \\
\text { (sociedad) }\end{array}$ \\
\hline Relación entre miembros & $\begin{array}{l}\text { Sentimiento de constituir un todo } \\
\text { Intereses emotivos y afectivos } \\
\text { Camaradería }\end{array}$ & $\begin{array}{l}\text { Camaradería, lazo familiar (comunidad) } \\
\text { Unión racionalmente motivada, compe- } \\
\text { tencia, cooperación (sociedad) }\end{array}$ \\
\hline Tipo de compromiso & Moral (don de sí mismo) & Moral ("“tarea' objetiva") \\
\hline Creencia & $\begin{array}{l}\text { Reconstrucción moral de la } \\
\text { nación, gesta patriótica }\end{array}$ & $\begin{array}{l}\text { Agenda valórica Legado económico- } \\
\text { institucional del régimen de Pinochet }\end{array}$ \\
\hline Nivel de cohesión & $\begin{array}{l}\text { Muy fuerte: comunidad identitaria } \\
\text { (generacional y de destino) en el marco } \\
\text { de sociedad segmentada }\end{array}$ & $\begin{array}{l}\text { Menos fuerte a pesar del mantenimiento } \\
\text { de una homogeneidad importante (redes } \\
\text { de reclutamiento) y del trabajo de } \\
\text { homogeneización del partido y la FJG }\end{array}$ \\
\hline Estrategia & Influencia & $\begin{array}{l}\text { Influencia, estrategia legislativa } \\
\text { (comunidad) } \\
\text { Lógica mayoritaria, control del } \\
\text { Ejecutivo (sociedad) }\end{array}$ \\
\hline
\end{tabular}

Fuente: Elaboración propia 